\title{
Dialogia
}

\section{Dentro da vida, fora do texto: leitura, família e literatura}

Inside life, outside the text: reading, family and literature

Anderson Silva

Graduado em Letras - Língua Portuguesa pela Universidade Estadual da Paraíba, com período sanduíche na Universidade de Coimbra. Mestrando em Linguística pela Universidade Federal da Paraíba, Paraíba, PB - Brasil. andersomrany031@gmail.com

Marcelo Medeiros

Doutor em Letras pela Universidade Federal da Paraíba, docente da Universidade Estadual da Paraíba, onde atua no Programa de Pós-Graduação em Formação de Professores, Paraíba, PB -

Brasil.

marcelomedeiros_silva@yahoo.com.br

\begin{abstract}
Resumo: Este artigo refere-se a um conjunto de atividades realizadas com alunos matriculados no $9^{\circ}$ ano de uma escola pública, situada na zona rural de um município paraibano. Tais atividades foram motivadas em virtude dos constantes comentários preconceituosos dos(as) alunos(as) contra certos arranjos familiares não-hegemônicos. Por isso, resolvemos trabalhar essa temática em sala de aula. Para tanto, escolhemos alguns textos literários que tematizassem as novas configurações de família na contemporaneidade. Como lastro teórico, apoiamo-nos em Mello (2005), Grossi, Uziel e Mello (2007) e Facco (2009), para os quais o conceito de família transcende o que já está arraigado socialmente. Os resultados obtidos foram satisfatórios, uma vez que, por meio da leitura e do debate sobre os textos literários com os quais trabalhamos, foi possível fazer com que os discentes refletissem sobre o que é família e ampliassem seus horizontes acerca da diversidade de arranjos familiares existentes em nossa sociedade.
\end{abstract}

Palavras-chave: Arranjos familiares. Ensino de literatura. Preconceito.

Abstract: This article discusses a series of activities undertaken with ninth grade students who attend public school in a rural area in the state of Paraíba in northeastern Brazil. Motivation for such activities was a response to the students' constant, biased comments against certain non-hegemonic family structures. Thus, the decision was made to address this topic in the classroom. Literary texts that explore new family configurations in a contemporary context were selected. Works by Mello (2005), Grossi, Uziel, and Mello (2007), and Facco (2009), for whom the concept of family transcends the current social configurations, were used as the literary foundation for the project. The results obtained were satisfactory. Through reading and debating the literary texts, the students reflected about the meaning of family and broadened their horizons with regards to the diversity of family structures that exist in contemporary society.

Key words: Family structures. Teaching literature. Bias.

Dialogia, São Paulo, n. 32, p. 266-277, maio/ago. 2019 


\section{Introdução}

O presente texto é fruto das ações do Programa Institucional de Bolsas de Iniciação à Docência (doravante PIBID) e vai se referir a um conjunto de atividades realizadas em uma turma do $9^{\circ}$ ano do ensino fundamental II da Escola Municipal de Ensino Fundamental Bento Tenório de Sousa, situada na zona rural do município paraibano de Monteiro. O trabalho realizado consistiu em um conjunto de aulas voltadas para a prática de leitura de textos literários que tematizassem assuntos que dificilmente circulariam no ambiente de sala de aula, tais como sexualidade, preconceito racial, violência, novas formas de configuração familiar.

Sobre este último assunto é que o presente trabalho se deterá, não só pela relevância social da temática, mas, sobretudo, porque, quando em sala de aula, nos rendeu significativos resultados, principalmente, para nós como bolsistas de um programa que visa ao desenvolvimento da atividade docente em alunos de licenciatura, bem como para os/as alunos/as que integravam a turma anteriormente referida.

Esclarecemos, antes, que a temática dos rearranjos familiares na contemporaneidade não tinha sido escolhida, inicialmente, como eixo de nossa intervenção pedagógica na referida escola, mas ela passou a ser o escopo de nossa intervenção depois da seguinte situação de sala de aula: na ocasião, discutíamos o cordel A vida secreta da mulher feia, de J. Borges, e, a certa altura do texto, apareceu a expressão "salada de frutas". Ao indagarmos a que remeteria no cordel a referida expressão, uma aluna respondeu que à família. Então, voltamos a perguntar o que a turma entendia por família. Um aluno respondeu que era "um local onde vive papai, mamãe e um filho". Voltamos a perguntar se família era um grupamento de pessoas nos moldes que o aluno apontara. Uma aluna respondeu que "não". Entretanto, a resposta dela não se opôs à do aluno. Pelo contrário, corroborou-a porque, segunda a aluna, respondeu que "quase todas as família têm dois filhos e não apenas um".

Novas perguntas foram feitas e percebemos que, naquele ambiente de sala de aula, a maioria dos discentes estava inserida em uma ordem discursiva em que o modelo de família tomado como parâmetro de referência, em torno do qual tudo o mais gravita, era o da família patriarcal: um pai, o provedor; uma mãe, mantenedora da harmonia da casa; e filhos, de preferência do sexo masculino ou, pelo menos, um do sexo masculino e outro do sexo feminino. Percebemos, então, que esses/essas alunos/as não tinham, ou porque desconheciam ou porque era impossível pensar em família fora do modelo patriarcal legitimado, conhecimento sobre os novos arranjos familiares vigentes na sociedade contemporânea. Por isso, uma vez finalizado o trabalho com o cordel de J. Borges, passamos a levar, para a sala de aula, textos literários que 
versavam sobre as relações familiares em nossa sociedade, em especial as que fugiam ao modelo de família nuclear burguesa: pai, mãe e filhos/as.

As respostas extraídas de sala de aula a partir de falas espontâneas dos alunos reafirmam o preconceito contra famílias que não pertencem ao padrão burguês referido. Era necessário, na situação em que nos encontrávamos, expandir os horizontes sociais e culturais dos alunos/as, para que não voltassem a proferir posicionamentos como os citados outrora.

Dessa maneira, considerando o que os/as alunos/as já conheciam, iniciamos nossas aulas com o conto "A caolha", de Júlia Lopes de Almeida, cujo modelo de família retratado, ainda que haja ausência da figura paterna, está em conformidade com o discurso do patriarcado. Em seguida, trabalhamos com Meus dois pais, de Walcir Carrasco, obra que retrata um casal heterossexual em momento de separação em que o pai, que convive com outro homem, luta pela guarda do filho. Por fim, encerramos nossa intervenção com a leitura e a discussão de Flor e rosa: uma história de amor entre iguais, de Benilda Brito, em que se conta a história de amor entre duas adolescentes.

Cremos que o trabalho que realizamos cumpriu a contento os objetivos que traçamos para ele no momento de nossa intervenção. Ou seja, conseguimos apresentar aos/as alunos/as novos modelos de família que, apesar de existirem no plano da realidade, são estigmatizados em virtude de crenças e valores culturais e sociais que não legitimam como positivo o que é diferente. Nossos/as alunos/as puderam, pois, perceber que existem outros laços de parentalidade, diferentes daqueles a que eles/elas estavam ligados. De acordo com Barroso e Machado (2010, p. 212), citando Haghughi (2004, p.5), parentalidade é um conjunto de "atividades propositadas no sentido de assegurar a sobrevivência e o desenvolvimento da criança". Dessa maneira, pensamos na parentalidade como um conjunto de atividades que asseguram o desenvolvimento da criança em ambiente familiar e social. Tal conceito vem reiterar que família não se define apenas pela origem biológica, mas, em especial, pelo conjunto de ações subjetivas e materiais que contribuem para o desenvolvimento físico, intelectual, afetivo e emocional do indivíduo.

Por fim, acreditamos que pudemos, a partir do debate em torno dos textos literários acima citados, fazer da sala de aula um espaço para o fomento não só da reflexão sobre, mas, sobretudo, do cultivo do respeito à diferença. É válido ressaltar, portanto, que a leitura de textos literários é imprescindível na formação do ser humano (COSSON, 2010). Afinal, "Se, por não sei que excesso de socialismo ou de barbárie, todas as nossas disciplinas devessem ser expulsas do ensino, exceto uma, é a disciplina literária que devesse ser salva, pois todas as ciências estão presentes no monumento literário" (BARTHES, 2007, p. 18-19). Dessa consciência "política" da 
importância do texto literário e, mais ainda, da relevância de abordagens de leitura adequadas à formação de leitores de literatura, é que advém nossa proposta de trabalho que tentou pensar acerca do preconceito dos discentes em sala de aula e maximizar a bagagem cultural da turma a fim de que o horizonte deles sobre o que era família fosse alargado.

\section{2 “A caolha” de Júlia Lopes de Almeida: leitura, discussão e reflexão na escola pública}

Para darmos início às atividades em sala de aula sobre os novos laços de parentalidade, não podíamos romper, abruptamente, com o que vínhamos trabalhando com a turma. Conforme sinalizamos na introdução, nossas aulas até então estavam centradas no cordel $A$ vida secreta da mulher feia, de J. Borges, a partir do qual os alunos e alunas estavam sendo levados a refletir acerca da construção social da beleza e da feiura. Considerando-se que, de certa forma, o feio é uma das temáticas do conto "A caolha", optamos por ele porque não perderíamos a discussão anterior acerca do que pode, em nossa sociedade, ser considerado feio ou belo, assim como, também, poderíamos dar início à nova proposta de discussão: os arranjos familiares na contemporaneidade, ainda que a história narrada se passasse no século XIX. Apesar disso, a trama desse conto nos era importante porque representa o modelo familiar tido como basilar em cujo centro está a figura do pai, ainda que ausente, ao redor do qual orbitam a esposa e o filho.

Acerca de "A caolha", lembremos que o conto foi publicado, originalmente, no volume intitulado Ansia Eterna. Com foco narrativo onisciente, a história trata da relação entre mãe e filho marcados por extrema pobreza. A mãe é mostrada como muito abnegada, para quem o filho é a razão da própria existência dela. Entretanto, apesar da devoção materna, o filho sente vergonha da mãe em virtude não só do defeito físico que traz consigo mesma e que é motivo da alcunha que recebe, mas também do aspecto grotesco que ela apresenta porque:

\footnotetext{
A caolha era uma mulher magra, alta, macilenta, peito fundo, busto arqueado, braços compridos, delgados nos pulsos: mãos grandes, ossudas, estragadas pelo reumatismo e pelo trabalho; grossas, chatas e cinzentas, cabelo crespo, de uma cor indecisa entre o branco sujo contato e o loiro grisalho, desses cabelos cujo contato parece dever ser áspero e espinhento; boca descaída, numa expressão de desprezo, pescoço longo, engelhado, como pescoço dos urubus; dentes falhos e cariados (ALMEIDA, 1940, p. 114).
}

A protagonista, apesar do aspecto repulsivo e grotesco descrito acima, é apresentada, ao longo da diegese narrativa, como uma mulher cujo modo de ser e de existir está coerente com o postulado patriarcal, visto que, mesmo diante das ingratidões do próprio filho, ela é uma boa mãe, referendando, assim, um estereótipo acerca da figura materna, o qual consiste em colocar a 
maternidade como o mais sublime exercício da mulher que deve zelar pelos cuidados físicos e morais do filho de forma abnegada e sem esperar nada em troca. Esse estereótipo assenta-se na visão de que a maternidade e o amor oblativo são inerentes às mulheres, o que é corroborado pelo modelo de mãe que o conto de Júlia Lopes de Almeida constrói ao longo da narrativa de $A$ caolha e desconsidera, portanto, que amor materno não se constitui como um sentimento inerente à condição de mulher (BADINTER, 1985).

Como sempre procedíamos em nossas aulas, iniciamos as atividades com uma motivação, estratégia a que recorremos para despertar a curiosidade dos alunos e impulsioná-los a participarem das ações que propomos. Por isso, antes da leitura de "A caolha", realizamos um "bingo" que consistia na escrita por parte dos/as alunos/as de cinco palavras que representasse o/a principal responsável da família deles/as. A escolha dos/as alunos/as deu-se pela figura da mãe, o que apontava para o quão estreitos podiam ser os laços entre eles/as e a própria mãe, mesmo em casos em que a figura materna era ausente. Depois, cada aluno/a se posicionou no lugar da figura a quem eles/as no primeiro da dinâmica haviam descrito com cinco palavras e escreveram cinco palavras que o/a definiram enquanto filhos/as. Em seguida, quando todas as palavras já estavam redigidas, o professor passou a sorteá-las e os/as alunos/as que, em cartela redigida por eles/elas mesmos/as, tinham as palavras sorteadas iam marcando-as, à moda de um bingo, na cartela improvisada. Ganhou a brincadeira quem completou primeiro a cartela. Depois desse momento lúdico, que visou sondar como os/as alunos/as viam os principais representantes de suas famílias, partimos, então, para a leitura do conto que narrava a história de uma mãe que é renegada pelo filho por ser, fisicamente, diferente das outras pessoas.

Para discutirmos o texto, foram feitas, oralmente, perguntas que procuravam levar os/as alunos/alunas a refletirem não só sobre aspectos estruturais da narrativa, tais como caracterização das personagens, identificação da vOz narrativa, como também avaliar o comportamento dos sujeitos retratados na história e as relações de afeto existentes entre eles e, por fim, pensar acerca do modelo de família representado na narrativa de Júlia Lopes de Almeida. O que denominamos como afeto é "ao mesmo tempo interior e exterior, pulsão e fenômeno, o que implica levar em conta o ânimo quanto corpo em seus modos particulares" (SODRÉ, 2018, p. 58), ou seja, corresponde a aspectos interiores e exteriores ao corpo. Dessa maneira, e de acordo com o que diz Sodré (2018), o termo "afeto" refere-se tanto a uma energia "pulsional", quanto a uma qualidade subjetiva inerente à espécie humana presente nos estados conscientes de (des)prazer.

Acerca desse último aspecto - o modelo de família descrito por Júlia Lopes de Almeida -, foi feita a seguinte pergunta: considerando-se que o modelo de família eleito como padrão em 
nossa sociedade é aquele em que temos a figura do pai como provedor, da mãe como esposa e cuidadora do lar e dos/as filhos/as, o modelo de família representado no conto em estudo corresponde a esse padrão de família nuclear burguesa?

As respostas a essa pergunta nos deram o mote para que pudéssemos prosseguir com a proposta de nossa intervenção: discutir sobre os diversos arranjos familiares existentes contemporaneamente. Como resposta, os/as alunos/as disseram que a família representada em "A caolha" foge ao padrão patriarcal porque, embora o pai esteja ausente, a presença da mãe e do filho leva-nos a crer em um modelo familiar de base heteronormativo. Ao darem essa resposta, percebemos que, na óptica dos/as alunos/as, existia apenas um único modelo de referência para o conceito de família, enquanto outros sequer foram aventados porque eram tidos como inexistentes.

Assim, os discentes até então desconsideravam que "os casais de homens existem; os casais de mulheres existem; os casais de homens e os casais de mulher com filhos - de relações anteriores, adotados, ou resultantes de novas técnicas reprodutivas-existem" (ALMEIDA, 2007, p. 160). Por isso, vimos que a nossa proposta de intervenção se fazia necessária naquela turma a fim de alargarmos os horizontes dos/as alunos/as de maneira que eles/as pudessem ver que o conceito de família não é tão rígido e fixo e que o modelo tomado como padrão não abarca todas as outras formas de família existentes em nossa sociedade.

\section{Da sagrada família aos novos laços familiares: leitura e reflexão no ensino fundamental}

Para continuarmos com o trabalho acerca da "família e seus inúmeros arranjos", prosseguimos com uma atividade que pedia que os alunos desenhassem a própria família. $\mathrm{O}$ objetivo dessa atividade consistia em perceber até que ponto a família de cada um/a de nossos/as alunos/as corroborava o modelo familiar patriarcal e burguês ou apontava para outras formas de parentela. A realização dessa atividade não contou, a princípio, com a participação de todos/as os/as alunos/as, visto que muitos/as deles/as apresentaram resistência em realizá-la, negando-se a fazê-la. Alguns/algumas até explicitaram os motivos da recusa à atividade, os quais estava relacionados a problemas em casa, enquanto outros alegaram que não pertenciam ao modelopadrão e, por isso, não queriam desenhar. Mesmo assim, outra parte da turma se dispôs a realizar o proposto. Os desenhos foram confeccionados e apontavam para uma diversidade de famílias que não, necessariamente, estão em conformidade com o modelo patriarcal burguês.

As ilustrações feitas em sala de aula revelaram que nem todos/as os/as alunos/as com quem trabalhamos fazem parte ou estão inseridos no modelo de família tomado como padrão de 
referência social e, por isso, valorizado como positivo. O primeiro desenho (da esquerda para a direita) ilustra uma família constituída apenas por mulheres como figuras principais de referência, o que nos faz pensar que o aluno responsável pelo desenho convive com sua mãe, avó e irmãs. Ou seja, com exceção dele, todos os membros familiares são do sexo feminino. O segundo não deixa dúvida: quem o fez convive apenas com a mãe e a irmã. O terceiro evidencia que o aluno convive apenas com a mãe, e o último desenho é o único que corrobora o modelo padrão tido como o da sagrada família: o pai ao centro, a mãe e os filhos ao lado dele. Esse último modelo de família é, então, universal e imutável (REIS, 1989), uma vez que “a família nuclear burguesa torna-se sinônimo de família. Outras formas, quando existentes, são consideradas, no máximo, estruturas que ainda vão se diferenciar em direção a esse modelo ideal de família” (REIS, 1989 p. $100)$.

Se há essa diversidade de laços de parentela, por que a resistência de nossos/as alunos/as em falar desse assunto. Ou melhor, de desenhá-lo? Esse receio pode advir de vários fatores, mas, talvez, ele seja decorrente de certa "vergonha" em não pertencer ao que, socialmente, é tido como positivo e valorizado. Lembremos que, acerca da família nuclear burguesa, há uma miríade de construções imagético-discursivas que a colocam como o padrão a ser seguido:

O reforço do estereótipo do modelo tradicional de família também é frequente. $\mathrm{Na}$ mídia, como nas propagandas de margarina, xarope ou de comida congelada, essa prática é usual. A mulher (branca) chega do trabalho, vestida de executiva e, com um sorriso com dentes perfeitos, esquenta, no micro-ondas, a lasanha congelada, enquanto a família (geralmente um homem bonito, branco, ainda de gravata, e um casal de crianças brancas, lindas e quietinhas) aguarda sentada à mesa (FACCO, 2009, P. 104).

Não só em nossa sala de aula, mas nas de outras escolas, encontramos uma diversidade de famílias e pessoas, já que, como aponta Facco (2009), a escola é o lugar do diverso não só quando o assunto é a expressão dos pensamentos, mas, sobretudo, quando olhamos para a pluralidade dos sujeitos que circulam no interior da instituição escolar e que possuem demandas sociais, econômicas, afetivas.

O desenho de uma das alunas, depois de pronto, nos chamou bastante atenção, principalmente porque sua autora foi a que mais se recusou a fazer o trabalho que propusemos. Como ficamos intrigados com o desenho, conversamos, em particular, com a aluna que o fez para saber o que ela expressou com a ilustração. A aluna se colocou como a garota no canto direito que está com o livro na mão. Criada pelos avôs, representados na parte superior do desenho, ela teve uma filha muito nova, a menina de rosa que está quase ao centro da figura, cujo pai não é o que está ao lado esquerdo do desenho, uma vez que o pai da criança é 
"desconhecido". A figura masculina que aparece no canto esquerdo do desenho é o pai da aluna. Se olharmos com mais atenção para essa figura, percebemos que a aluna ilustrou o pai como se ele estivesse de costas para ela e para todos os demais membros da família. Segundo nos relatou, a aluna foi abandonada pelos pais e criada pelos avós paternos. Como não conhece a mãe, ela não a representou. Nesse caso, a mãe aparece como ausência. Já o pai da aluna é conhecido, mas vive distante dela. Por esse motivo, ele está desenhado meio de longe e de costas. Foi essa a forma como a aluna encontrou para representar, segundo ela, o desprezo, abandono que sofre do pai, assim como, possivelmente, sua filha sofrerá, já que mãe e filha são mulheres abandonadas pelo masculino.

Após as discussões sobre os desenhos por meio dos quais os alunos representaram suas famílias, pedimos-lhes que, ainda por meio de desenhos, ilustrassem famílias que eles/as considerassem que são diferentes porque não confirmam o que é dito como modelo aceitável socialmente. Essa atividade foi intitulada de \#MinhaFamíliaExiste. Assim como na atividade anterior, os alunos apresentaram também resistência para realizar essa outra. Alguns chegaram mesmo a se recusar a fazê-la. Entretanto, outros fizeram-na e, a partir do desenhos produzidos, foi possível tecermos algumas reflexões acerca de como viam os laços familiares no cotidiano deles. A título de exemplificação, houve desenhos que representaram um modelo de família no qual existia apenas a figura da mãe e dos filhos. Outro que mostrava uma mulher e cachorrinho sinalizava que família podia ser formada por um ser humano e um animal. Alguns/as alunos/as fizeram desenhos que mostravam que uma família podia ser constituída por sujeitos do mesmo sexo. Nesse último caso, estavam representados como símbolos de família dois homens e uma criança. Reiteremos que os desenhos sobre os quais estamos nos detendo foram, uma vez depois de elaborados pelos/as alunos/as, socializados e discutidos em sala de aula a fim de conscientizarmos de que família é algo muito mais diverso do que o modelo instituído como padrão.

Como forma de confirmarmos o que anteriormente apontamos, principalmente no tocante à descrição dos desenhos dos alunos, citamos as palavras de Dias (2018, p. 1):

\footnotetext{
Existem diversos tipos de entidades familiares: famílias matrimoniais, decorrentes do casamento; famílias informais oriundas da união estável; famílias homoafetivas iniciadas a partir do elo afetivo entre pessoas do mesmo sexo; famílias monoparentais constituídas pelo vínculo afetivo entre um dos genitores com seus filhos; famílias anaparentais baseadas no vínculo existente entre irmãos diante da ausência dos pais; e ainda, a família "multiespécie" novidade no Direito de Família que merecerá profundas análises diante do tema aqui proposto.
} 
Diante dessa discussão exposta pela autora, reiteramos que inúmeras são as ramificações do que se compreende por família. Assim, há famílias decorrentes de casamento, famílias informais, famílias homoafetivas, famílias monoparentais e até mesmo as famílias "multiespécie".

A discussão sobre família não se encerraria com a produção dos desenhos comentados acima. Ela deveria prosseguir com a leitura e a discussão de duas obras literárias voltadas para o assunto: Meus dois pais, de Walcyr Carrasco, e Flor e rosa: uma história de amor entre iguais, de Benilda Brito. Entretanto, alguns eventos, tais como paralizações, greves, inviabilizaram o prosseguimento de nossa proposta, visto que o encerramento do ano letivo estava muito próximo e não teríamos mais tempo para darmos continuidade ao trabalho. Apesar disso, por acreditarmos na viabilidade do que pensamos em executar, mas, principalmente, por termos a consciência de que a temática em discussão, bem como as obras que escolhemos, precisam circular em sala de aula a fim de não apenas apresentar outros laços de família, mas de, sobretudo, cultivar o respeito à diferença, é que passaremos a expor como sugestão as demais etapas do trabalho que ficou em suspenso e que pensamos em retomar, em outro momento, quando estivermos em sala de aula como regentes de ensino.

Depois que fizéssemos as leituras dos livros citados acima e um trabalho de interpretação com os/as alunos/as, iniciaríamos um trabalho em que iríamos confrontar a representação de família divulgada socialmente com as que trazem outros textos, tais como vídeos, fotos, a fim de os/as alunos/as fossem levados a pensar o quão difícil é romper com a ordem do discurso vigente e procurar migrar da margem para o centro, não para ocupar o lugar deste, mas para ter uma possibilidade de vez e voz.

Em seguida, cobraríamos da turma a confecção de cartazes que mostrassem a possibilidade de amar ao próximo da maneira como ele é. Após a produção, viria a apresentação para os/as demais colegas. Tendo isso em mãos, os cartazes seriam expostos na escola não apenas como uma maneira de mostrar o trabalho, mas alertar as pessoas para o preconceito que ainda perdura na sociedade e que procurar negar a legitimidade de outros arranjos familiares. Ao agirmos assim, como educadores, estamos tomando uma postura política que parte do pressuposto de que compete à escola fomentar a consciência crítica de seus/suas alunos/as e ensiná-los/as a desconfiar do que é naturalmente aceito. Em outras palavras, é necessário que "a escola, educadores e educadoras assumam a tarefa de combater os preconceitos e as violências, construir o respeito à diversidade e à equidade [...] através de práticas educativas [...]" (SANTOS, 2013, p. 439). 


\section{Considerações finais}

Da experiência aqui relatada, é importante destacarmos que a temática em discussão precisa, ainda, circular no ambiente escolar, uma vez que a escola não é uma redoma de vidro alheia à vida, ao mundo lá fora de onde vêm e vivem os/as alunos/as que por ela circulam. A discussão em torno dos rearranjos familiares e das outras formas de parentela advém ainda da necessidade da escola de extrapolar os limites do heterocentrismo familiar, visto que, como "as expressivas transformações sociais, políticas, culturais e econômicas do último século têm afetado, sobremaneira, a família” (MELLO, 2005, p. 27), essas mudanças precisam ser conhecidas por nossos/as alunos/as a fim de que possamos formar cidadãos e cidadãs críticos/as, mas, principalmente, abertos à diversidade, ao respeito à diferença. Para ilustrar o que dissemos, gostaríamos de nos reportar a um dos desenhos feitos por um de nossos alunos. Ver a produção desse desenho apontou, para nós, o quão positiva foi a discussão porque no lugar do ódio fomentou o respeito ao que, em alguns discursos reacionários e preconceituosos, deve estar sempre à margem. Ao lado do desenho que o aluno fez, havia a seguinte mensagem: "Não existe família sem amor. O sorriso de quem ama é lindo, mas o sorriso de quem sofre é ainda mais lindo, pois além de sofrer, tem a capacidade de sorrir".

Ao final das atividades, os discursos dos alunos estavam perpassados por uma percepção da necessidade de valorização da diferença, visto que, frequentemente, afirmavam que "não existe família sem amor" e as ilustrações criadas pelos discentes sinalizavam para a família como um agrupamento de pessoas marcadas pela diversidade. Por isso, gostaríamos de finalizar o nosso texto, reiterando que, ainda que a nossa proposta de intervenção tenha ficado inconclusa, percebemos a necessidade de a escolar abrir um espaço para discussões sobre assuntos que são vistos como tabus e, consequentemente, de deixar de resistir "aos novos tempos, às novas reflexões que se fazem prementes, e de optar por permanecer em uma posição aparentemente desvinculada dessas discussões, embora isso seja impossível, já que elas permeiam todos os espaços e relações sociais" (FACCO, 2009, p. 22). É diante disso que justificamos que as discussões que empreendemos em sala de aula, os textos que lemos e pretendíamos ler precisam, cada vez mais, se fazer presentes na escola a fim de que possamos manter em processo ações que considerem a educação como "lugar de crítica, diálogo, criação e transformação cultural" (SANTOS, LIMA, GOMES, LIMA e MENDES, 2013, p. 429).

\section{Referências}

ALMEIDA, Júlia Lopes de (1940). A caolha. In: ALMEIDA, Júlia Lopes de. Ânsia eterna. Rio de 
Janeiro: A Noite.

ALMEIDA, Miguel Vale de (2007). O casamento entre pessoas do mesmo sexo. Sobre "gente remotas e estranhas" numa "sociedade decente". In: GROSSI, Mirian; UZIEL, Anna Paula; MELLO, Luiz (orgs.). Conjugalidades, parentalidades e identidades lésbicas, gays e travestis. Rio de Janeiro: Garamond, p. 153-168.

ANDRADE, Andreza de Oliveira (2013). A educação que se pergunta pelo corpo: debatendo gênero, sexualidade e homofobia na escola. In: SILVA, Antonio de Pádua Dias da; RIBEIRO, Maria Goretti. Rumos dos estudos de gênero e de sexualidades na agenda contemporânea. Campina Grande: EDUEPB, p. 417-428.

BADINTER, Elisabeth (1985). Um amor conquistado: o mito do amor materno. Rio de Janeiro: Editora Nova Fronteira.

BARROSO, Ricardo G; MACHADO, Carla (2010). Definições, dimensões e determinantes da parentalidade. Revista psychologica. Coimbra, Portugal, n. 52, v.1, p. 211-229.

BARTHES, Roland (2007). Aula: aula inaugural da cadeira de semiologia literária no colégio de França, pronunciada no dia 07 de janeiro de 1977. Tradução de Leyla Perrone-Moysés. 15ed. São Paulo: cultrix.

BRITO, Benilda (2011). Flor e rosa: Uma história de amor entre iguais. Belo Horizonte: Mazza edições.

CARRASCO, Walcyr (2010) Meus dois pais. São Paulo: Ática.

COSSON, Rildo (2010). O espaço da literatura na sala de aula. In: COSSON, Rildo; MACIEL, Francisca; PAIVA, Aparecida (orgs.). Literatura: ensino fundamental. Brasília: Ministério da educação, secretaria da educação básica, p. 55-68.

DIAS, Maria Ravelly Martins Soares (2018). Família multiespécie e direito de família: uma nova realidade. Revista Jus. Texto disponível em: < https://jus.com.br/artigos/67381/familiamultiespecie-e-direito-de-familia-uma-nova-realidade/1 $>$.

FACCO, Lúcia (2009). Era uma vez. um casal diferente: a temática homossexual na educação infanto-juvenil. São Paulo: Summus.

HOCHUGHI, M. Parenting: a dynamics perspective (2004). In: HOGHUGHI, M; LONG, N. Handbook of parenting: theory and reseach for practice. London: Sage, p. 1-18.

MELLO, Luiz (2007). Matrimônio entre pessoas do mesmo sexo na Espanha. Do perigo social à plena cidadania, em quatro estações. In: GROSSI, Mirian; UZIEL, Anna Paula; MELLO, luiz (Orgs.). Conjugalidades, parentalidades e identidades lésbicas, gays e travestis. Rio de Janeiro: Garamond, p. 169-188.

MELLO, Luiz (2005). Para além do heterocentrismo na família. In: MELLO, Luiz. Novas família. Rio de Janeiro: Garamond, p. 25-50. 
PASSOS, Maria Consuêlo (2013). A constituição do parental na família homoafetiva. In: SILVA, Antonio de Pádua Dias da; RIBEIRO, Maria Goretti. Rumos dos estudos de gênero e de sexualidades na agenda contemporânea. Campina Grande: EDUEPB, p. 299-307.

REIS, José Roberto Tozoni. Família, emoção e ideologia (1989). In: LANE, Silvia T. M; CODO, Wanderley. Psicologia social: o homem em movimento. São Paulo: Brasiliense.

SANTOS, Anita Leocádia Pereira dos et al. Relações de gênero e homofobia nas escolas: um estudo no brejo paraibano (2013). In: SILVA, Antonio de Pádua Dias da; RIBEIRO, Maria Goretti. Rumos dos estudos de gênero e de sexualidades na agenda contemporânea. Campina Grande: EDUEPB, p. 429-440.

SODRÉ, Muniz (2018). As estratégias sensiveis: afeto, mídia e politica. Rio de Janeiro: Mauadx.

Recebido em: 23 maio 2019 / Aprovado em: 25 jun. 2019

\section{Cite como}

SILVA, Anderson; MEDEIROS, Marcelo. Dentro da vida, fora do texto: leitura, família e literatura. Dialogia, São Paulo, n. 32, p. 266-277, maio/ago. 2019. Disponível em: https://doi.org/10.5585/Dialogia.n32.13970. 